\title{
The Hypotheses Testing Method for Evaluation of Startup Projects
}

\author{
Dmytro Shestakov ${ }^{1}$ \\ ${ }^{1}$ Finance Department, Kyiv-Mohyla Business School, National University of Kyiv-Mohyla Academy, Ukraine \\ Correspondence: Dmytro Shestakov, PhD, Kyiv/01033, Ukraine. Tel: 380-664-796-922. E-mail: ds@thinkera.pro
}

Received: October 4, 2021; Accepted: December 4, 2021; Published: December 6, 2021

The research is financed by Thinkera Ventures.

\begin{abstract}
This paper suggests new perspective to evaluating innovation projects and understanding the nature of startup risks. Author consider five principal hypotheses that underlie every innovative project that comprise a bunch of respective assumptions to manage startup risks in a proactive manner. Suggested approach spots the light on a project's uncertainties and risks, embedded investment and managerial options, and enables more comprehensive and accurate evaluation of innovation. The Hypotheses Testing Method enables to estimate risks and attractiveness of a startup project in a clear and fast manner. It replaces unclear traditional techniques like NPV and DCF, avoiding heavy cash flow modelling.
\end{abstract}

Keywords: innovation management, startup, risk management, startup valuation

\section{Introduction}

Solving particular problems and challenges, often even unarticulated, innovation bring to their customers certain values (Gans, 2016; Goffin \& Mitchell, 2017; Chesbrough, Lettl \& Ritter, 2018; Rong \& Xiao, 2016; Cesário \& Fernandes, 2019). No matter what they are, a brand new or slightly bigger than existed before, these values always exist in the form of new products (Shestakov, 2018; Shestakov \& Poliarush, 2019; Zhou \& Li, 2012; Nagji \& Tuff, 2012; Spanjol, 2012; Marion \& Fixson, 2020). Today, there is a number of approaches to estimate such a value such as discounted cash flow, venture capital method, real options approach, comparison method, competitive losses, matching method, etc. (Damodaran, 2002; Kodukula \& Papudesu, 2006; Smit \& Trigeorgis, 2004; Cassia, 2007; Que \& Zhang, 2020; Casadesus-Masanell \& Zhu, 2013; Drucker, 2013). However, while researchers compare these and other evaluation techniques in terms of their accuracy, dispersion of possible results, ability to describe uncertainty whatever (Damodaran, 2002; Cassia, 2007), specifics of evaluating an innovation project and its product remains blurred. In other words, there is an explicit shift of focus on the result of an innovation project, but not on the process of its creation and development.

Meanwhile, evaluating a project value mostly relying on late stages where the product already exists, means that risks associated with earlier stages to be absent or simply ignored. Conventionally, this issue is solved by using a discount rate that is supposed to reflect the risks of the whole project aggregated in one figure (Correia, 2007; Chambers \& Echenique, 2018; Ohlson, 2003; Drucker, 2013), which often goes in with decision tree and scenario analyses (Smit \& Trigeorgis, 2004; Brandão \& Dyer, 2005; Sick \& Gamba, 2005). Although, still focusing primarily on the final results of the project, investors remain incapable of understanding the nature of pertaining project risks and so have less managerial capabilities to manage them.

In the meanwhile, being a set of hypotheses (Hurst, 1982; Melkas \& Harmaakorpi, 2011; Kerzner, 2019), an innovation project can be further decomposed into a number of assumptions (Sandström, 2014; Tsang, 2006; Berglund \& Sandström, 2013) related to a particular stage (e.g. prototyping, MVP, basic and full version development, market entry market penetration; (Furr \& Dyer, 2014; Tohidi, 2012; Taylor \& Levitt, 2007) and therefore can be tested to dispel uncertainty and to determine the degree of inherent risk in course of its evolution (McGrath, 2010). Therefore, an innovation project evaluation should account all stages of creating an innovation product through the prism of the underlying assumptions, in order to understand the nature of its risks and to estimate its value properly considering the variety of available managerial options.

The closest methodological approach being used nowadays to account uncertainties and risks of an innovation project throughout its lifetime is Stage Gate model (Ettlie \& Elsenbach, 2006; Cooper, 2010; Cooper, 2011; Cooper, 2014; Cooper, 2016; Cooper \& Sommer, 2016) that focuses on the innovation process in the whole and work it 
out from the perspective of six stages. Whereas, assuming each stage to be designed to collect specific information in order to dispel uncertainty and risks, Stage Gate model heavily relies on a waterfall logic that eliminates managing risks in a proactive manner via agile methodologies. Without suggesting any particular set of hypotheses basically intrinsic to a project, the model excludes the possibility to test them from the very beginning, even though they relate to later stages. Moreover, the stages used in Stage Gate approach are quite general, which doesn't anticipate a delivery logic of a project, which makes its evaluation more complicated. On top of all of that, even though Stage Gate model is the closest existing methodology to cover uncertainties and risks of an innovation project, it also doesn't enable to assess its risks intrinsic to each stage and evaluate its value.

This paper proposes to look at innovation from a conceptual point of view concentrating on primary stages of their creation and development towards product implementation and marketing using incremental delivery perspective. Shifting the focus from end results to the complex delivery process, the authors propose a new approach to understanding innovation projects and their risks in a wider perspective than it is used to being considered. Proposing the Hypotheses Testing Method, this study suggests a set of hypotheses that cover any innovation project and all aspects of creating new products. The authors assume that in its fullest configuration an innovation project always consists of the five high-level hypotheses that can be further decomposed into smaller assumptions. These are a team competency, technological capability, customer value, business model, and market depth hypotheses which have convexities and overlap during the project progress depending on the degree of innovativeness, and so enable managing risks in a proactive manner testing them from the very beginning of a project's creation.

Understanding decomposition of each hypothesis, reveals a more detailed picture of a project's uncertainties and risks, variety of available investment and managerial options, and enables more comprehensive and accurate evaluation of innovation. The Hypotheses Testing Method is practically applicable to any project, which makes it a conceptual basis for creating and development of innovation by perceiving their risks in a much clearer manner and enabling assessment of their subtle value.

\section{Method}

At all times, the engine of progress and development was the invention of something new, which did not exist before. However, it is important to understand that all innovations created are designed to meet existing (and nonexistent) human needs. In fact, each innovation brings its own unique value to the customers in terms of solving specific problems. Different approaches to assessing the future development cost have appeared with the general availability of investments in the development of innovations. In order to be able to invest in the development of innovation (creation of new products), it is necessary to assess this opportunity. The existing assessment models are reduced to a rather narrow emphasis - the finished product, that is, the scientific literature shifts the emphasis on assessing the product, that is, the result of an innovation, omitting the entire life cycle of creating an innovation with all the inherent risks and uncertainties.

When researching an innovation project as a form of innovation activities (Chesbrough, Lettl \& Ritter, 2018) for the development and implementation of innovations, researchers often deviate from the specific distinctive features of the innovation project that is a complex system of interdependent and interconnected resources, deadlines and implementers of activities aimed at achieving specific goals (objectives) for the priority areas of science and technology (Frank, 2016; Hartwig \& Mathews, 2020).

It is careless to assess the future cash flows of an innovative project using classical financial methods, because omitting the entire period of innovation development and evaluating only the product sales stage (scaling), standard Net Present Value (NPV) significantly reduces the project investment attractiveness and embedded flexibility to minimize sunk costs and maximize upsides, and is not an appropriate method of evaluating projects that are subject to significant uncertainty and risks.

Yes, this method considers a certain risk, but it is stable throughout the entire project and is enclosed in a discount rate, which does not reflect the reality of all stages of an innovative project. Without dividing the project into risks of different nature, the assessment will be linear and may give significant deviations from the output results. Even more advanced methods like Decision Tree Analysis and Scenario analysis include a constant discount rate. Why is it important? Due to its limitations, the discount rate cannot include the risks of a complete abandon of the project at the early stages, that is, a working prototype and Minimum Viable Product (MVP). This leads to the fact that the estimated income at the last project stages will be equal to 0 (after all, the product has not been launched, which means there is nothing to sell), and the losses will be equal to the amount of funds spent on the project. In fact, the NPV model based on the discount rate cannot include risks in the early stages of the project. Understanding the nature of the risks of an innovative project will allow to shift the emphasis in the assessment of innovation at all its stages, from the idea to scaling the finished product, thereby identifying and highlighting possible clusters 
of risks at the beginning of an innovative project. Focusing on all the risks of an innovative project regardless of its stage, separating certain risks depending on their impact on the outcome of the stage and the project as a whole through testing the relevant hypotheses, will allow investors to understand the nature of pertaining project risks and thus ensure the managerial flexibility in innovation project risk management.

A characteristic feature of projects whose goal is to create innovation is the dependence of uncertainty and, as a consequence of risks at the initial stages of creating an innovation, on the degree of innovation project (Bowers \& Khorakian, 2014; Keller, 2017; Chappin et al., 2019; Kock \& Gemünden, 2020; Mathews \& Russell, 2020; Young, 2020).

Strategic decisions within the innovation project are made in the face of uncertainty, which is an integral characteristic of innovation (Wang, 2017; Shestakov \& Poliarush, 2019; Loch, 2007). Analyzing uncertainty, it should be noted that it relates to innovations directly through the process of their creation within the project, since it is usually not obvious what kind of methodologies, techniques and tools should be used to create the innovation; and that the result of the innovation project is unknown and may deviate significantly from the expected one (Nagji $\&$ Tuff, 2012; Shestakov, 2018).

The 'uncertainty factor' of an innovation project generates a certain range of hypotheses that underlie the project's value and return on investment. Upon calculating the cash flows after the implementation of the project as well as upon applying the appropriate discount rate (Latimore, 2002; Zizlavsky, 2014), investors calculate the net present value (NPV) of the investment, which enables making the appropriate decision to participate in the project or not (Ohlson, 2003; Smit \& Trigeorgis, 2017). However, in case of innovation projects, the application of the classical method of cash flows estimation leads to the multiplication of uncertainty, which is the way of adding new assumptions to a set of other uncertainties. It is so due to the fact, that the cash flow assumption is derived from the successful implementation of the project at such stages as idea development, prototyping, minimum viable product (MVP) and basic version development, business model testing and market entry, only after that the project moves to the stage of scaling (testing the market depth), at which it begins to generate cash flows. That is, to determine the degree of inherent risk, it is necessary to separate all types of risks between the stages of the project and evaluate them separately (both for the early stages and for the later ones).

Stage Gate model (SGM) as the closest existing methodology to cover uncertainties and risks is a project management methodology (Cooper, 2016; Cooper \& Sommer, 2016). The Stage-Gate process is based on the belief that product innovation begins with ideas and ends once a product is successfully launched into the market. The first 2 stages of an innovative project under SGM ('Scope' and 'Design') affect market research and detailed investigation involving primary research and involve voice of customer approach in a slightly narrow form, which means that there is no progress in reducing the level of uncertainty in the context of the customer value - it is still the 'black box'. The third stage - 'Develop' - combines all development, it is, in fact, an innovative project from the beginning of the prototype development to the creation of a finished fully functional product. Confirmation of consumer value occurs only at the 4th stage of this method ('Scale Up'). However, in fact, all capital at risk is concentrated in stage 3 under the SGM, which makes it possible to lose all funds for the project after the hypothesis of customer value is not confirmed. The last stage under SGM i.e. 'Launch' assumes the beginning of full-scale operations or production, marketing and sales (commercialization phase), which is really the final stage of any innovation project.

After completion of each stage the gate follows, where the project leader or manager decides to start the next stage or abandon the project (Go/Kill decision). However, it is worth considering that the risks of unconfirming the hypotheses, which are included in stages 4 and 5, must be analyzed not in fact, but at the initial stages of the project. This will minimize the losses of the investor and competently bring the project to completion, if the hypotheses regarding the team competence, technological capability, customer value, business model and market depth are confirmed. SGM does not fully reveal the depth of the risks of creating an innovation but focusing on the process of creating innovation makes this model the closest to the approach proposed in this work.

In case of project management, the innovativeness of SGM is that it adds more flexibility to classical waterfall logic due to the possibility of adding cyclicality at the stages of the project. It's more about project management, not about innovation project evaluation. In case of risk management, SGM not aimed at reducing the level of uncertainty for competent project risk management and does not provide answers for a more substantive understanding of the risks of an innovation project.

We use proactive agile instead of waterfall logic (which reflects the SGM logic) to show the impact of certain risks on the result of each stage of the project in interactive and iterative logic. Using this approach, it is possible to manage risks by analyzing in detail all the convexities for each hypothesis. And this, in turn, enables the investor 
to overestimate the probability of a negative outcome for each type of risk, thereby more clearly managing the uncertainties of creating an innovation. Understanding the risks of an innovation project, from the very beginning of an innovation project there is an opportunity to work them out at each stage by iterations, which is a methodologically clear systematization of the risk management.

When the process of measuring is done correctly, it will be clear that a company is either moving the drivers of the business model or not. If not, it is a sign to pivot or make a structural course correction to test a new fundamental hypothesis about the product, strategy and engine of growth.

However, it is worth noting one significant distinguishing characteristic in the approach proposed in this article and the lean methodology. Lean is a methodology for quickly going through the early project stages, namely creating a working prototype and MVP. This technique can really give an understanding of the possibility of implementing an innovative idea, but it does not give answers to the possibility of product commercializing. In other words, lean touches on the technical side of the innovation project and bypasses the business side. This is the key difference - after all, a technically working version of the product, without promotion, commercial component and market conquest, will not have exponential growth. In fact, the lean approach does not come close to understanding the business risks of the project. The approach proposed in this work corrects this bulge, completely covering all the main risks of going through all stages of an innovative project, both technical and business.

Instead of quantifying the depth of the innovative product market and building a detailed financial cash flow model, we emphasize to shift the focus to qualitative analysis of key assumptions at each project stage i.e. idea - prototype - MVP - market entry - product scaling and analyze how they can be checked as early as possible. Based on lean methodologies to innovation process and considering all the possibilities and sides of the SGM approach, this paper proposes an independent approach. We will outline the main hypotheses on the way of innovation project implementation and innovation creation.

Hypothesis 1: Team Competence (H1). The project team is a group of responsible people who form the basis for further innovation development activities, directly participate in innovation processes, and perform tasks for the creation, implementation, and realization of innovation products. The technical part of the team should be able to create a prototype, MVP and a basic version of the innovation product for further implementation. The business part of the team (entrepreneurship, management, marketing, business development, sales) should be able to formulate the concept of the product, to manage effectively its development, to create and implement the strategy of sales and scaling of the product not only in regard to customers but also non-customers, i.e. potential customers of the given product, who for some reason do not use available alternatives.

The goals and specific roles of the innovation team depend on the type, size and scope of the project as well as activity of the company. In order to innovate, companies need a driving force from within, which is an experienced team that thinks through innovation categories, implements the right technologies and best practices for innovation processes. 'In the R\&D context, a critical set of roles are around leading teams to promote good team spirit, trust and support, and to build group dynamics and processes that encourage necessary teamwork to turn creative ideas into innovation products and services' (Paulsen, 2009).

The team competence hypothesis is present at every stage of innovation creation: starting with the idea till the scaling of the product created. This means that the team competence generates end-to-end risks throughout the life cycle of the innovation project. Due to the different orientation of the technical and business parts of the team as well as diverse activities throughout the implementation of the innovation, the risk impact at different stages of the innovation project is different. At the prototype, MVP, and basic version development stages, the technical team competence hypothesis (H1.2) has a greater impact than the business team competence hypothesis (H1.1), since the main tasks at these stages are creating the prototype, MVP, and basic version respectively and require technical expertise. The business-focused team of a project usually begins to dominate after the business model hypothesis (H4) testing during a project basic version stage (see fig. 1), while the technical team developed a product at the previous stages continues focusing mainly on supporting and refining the product.

Hypothesis 2: Technological Capability (H2). Innovation is created in a certain time period, where appropriate technological solutions and theories dominate and are available for use. A technology maturity can significantly affect the results of the innovation project and product implementation. The technological capability required to create and manage technical changes includes skills, knowledge and experience that often (but not always) differ significantly from those required to operate existing technical systems (Bell \& Pavitt, 1995). 'The technology development capability allows the firm to choose and to use technology with strategic purposes, to create new methods, process and techniques, and mostly, to offer new [innovation] products.' (Zawislak, 2012). 
The technological capability hypothesis also involves assessment of the technology's complexity, its practical applicability, the development level of supporting technologies that in one way or another affect the use of the underlying technology. Also, an innovation product may consist of several technological solutions, which implies multilayered levels of complexity, practical applicability, development of basic and supporting technologies. In fact, diversification of risks of different technological solutions does not reduce the whole uncertainty of the innovation project, but rather creates multilevel risks that must be identified and managed by testing the $\mathrm{H} 2$. One of the main success factors for innovation products is the technical component, which leads to the high efficiency of the innovation product (Garcia \& Calantone 2002).

Incremental development of a product through prototyping and MVP, with a limited basic functional set, means creating an initial version of the innovation in order to enable potential customers to evaluate key features of the newly created product and to prove or deny its value (testing the customer value hypothesis (H3)), which allows managers to make a respective pivot or exit a project and so to fix sunk costs at a minimum level. 'MVP allows entrepreneurs to focus more on knowing who their customers are, what habits they have, and how to attract and retain them.' (Trimi, 2012). Technological risk reduces as you progress through the innovation project development stages, which means that at the prototype stage the risk is the highest, and at the market entry and scaling stages it is the lowest.

It is obvious that technologies used for creation of a prototype, MVP and basic version of a product can be complex, and their practical applicability and level of development can affect the technological capability to accomplish necessary tasks and therefore to achieve the project targets.

Hypothesis 3: Customer Value (H3). 'Customer value has been widely recognised as a key factor in organisational management, marketing strategy and customer behaviour.' (Sánchez-Fernández \& Iniesta-Bonillo, 2009). All processes of an innovation project are aimed at meeting existing customers' needs and/or creating a new, previously unknown, demand. Pinto and Mantel, based on the research of the 97 failed projects, identified a project value and customer satisfaction as two out of three main causes of failure (Pinto \& Mantel, 1990). The marketing component reflected in the degree of customer commitment to the product is one of the basic concepts of innovation success (Garcia \& Calantone, 2002). The essence of the customer value hypothesis (H3) is to confirm the value of the newly created product and the willingness to use it by targeted customers.

A new product is valuable if it offers a better way to solve a problem. But even if the product has some functional, emotional or social benefits in comparison to other alternatives, a customer before acquiring the product will also take into account its cost, time and efforts needed to use it. That is, value is not just the quality and quantity characteristics of a product against those available on the market, it is the willingness of customer to buy this product within the offered price model, which is reasonable to be tested before market entry and as a part of the business model hypothesis testing.

Hypothesis 4: Business Model (H4). 'Technology by itself has no single objective value. The economic value of a technology remains latent until it is commercialized in some way via a business model.' (Chesbrough, 2010). 'The essence of a business model is in defining the manner by which the enterprise delivers value to customers, entices customers to pay for value, and converts those payments to profit' (Teece, 2010). Following the project logic, the purpose of making a business model is to confirm the willingness of customers to buy a product for the offered price model (based on a particular value chain) and using designed marketing channels. Despite the fact of being competitive, an innovation product may not find its customers through a poorly designed business model.

The business model of the company working on the implementation of the innovation should give clear answers to the questions: how the product is created, how it is sold and delivered, how it is supported and maintained, how users are attracted, and how the company will earn from innovation (monetization model). In the absence of a proper business model, technologically innovative product will hardly enter the market, not to say creating a new one, and disruptive innovation will not 'disrupt' the target market.

Hypothesis 5: Market Depth (H5). An investor always looks at an innovation project in terms of its commercial scalability. Innovations aimed at satisfying a narrow customer category generally do not have significant demand among venture capital investors.

The uncertainty about the market depth is related not only to the unpredictable volumes of possible revenues, but also to the sources of revenue. The market depth hypothesis is tested with regard to i) type, level, form, and degree of innovation, the creation of which is envisaged by an innovation project, since different combinations of innovation characteristics may imply significant differences in the breadth and depth of a target market; ii) the value of the product being developed and the ability to meet the specific needs of customers; iii) scalability and 
access to new markets of the newly created product. Assumptions outlined at the market entry stage allow to be reviewed and pivoted upon incoming data, and so to mitigate market risks.

Fig. 1 below illustrates the five hypotheses that need to be tested for in-depth understanding of innovation project risks.

\section{Investments}

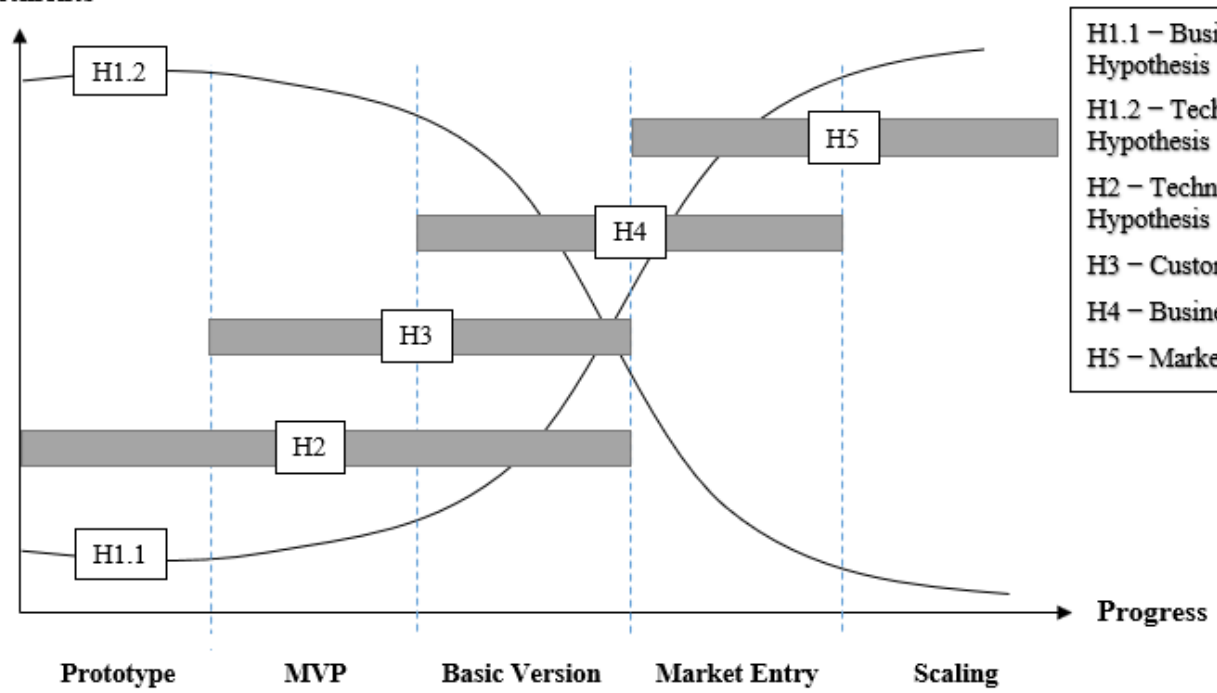

Figure 1. Hypotheses of an innovation project in terms of product evolution

\section{Results}

The 5 main hypotheses presented and described above combine most of the risks of implementing an innovation project. It is possible to overestimate an innovation project based on a qualitative analysis, however, it is also possible to use more visual calculations that will help not only to compare the project value estimated with the inclusion of a hypotheses conceptual model with the project value estimated by the Discounted Cash Flow (DCF) method, but also to expand the horizon of risks to minimize losses and focus on those project risk bulges that can lead to the project abandon.

Further, the real options method will be used in paper as a proxy for the quantitative assessment of an innovative project with the inclusion of 5 hypotheses at different stages of the innovation project. The calculations below reflect the logic of the project evaluation process, if the hypothesis testing approach at each stage of innovation creation is used.

Thoroughly analyzed theoretical basis for the ROA (Real option analysis) methodology in innovation projects evaluation and interpreted practical significance of the results obtained, this section represents the case study with a detailed explanation of all stages of evaluation and results on each project life cycle. By detailing and quantifying the hypotheses suggested above, managerial flexibility over the life cycle of an innovation project will be estimated to fully understand the competitive advantages of the valuation method used.

The Innovation Company interested in investing into a breakthrough innovation project considers the product features, and functionality to be developed will significantly outweigh existing solutions and solve a set of specific customer problems more efficiently and at a less cost.

According to the classic DCF approach to assessing investment attractiveness the project team proposes to invest $\$ 500,000$, namely $\$ 150,000$ in the product basic version development during the 1st year, $\$ 100,000$ in market entry stage during the 2 nd year, $\$ 150,000$ and $\$ 100,000$ in marketing during the 1 st and the 2 nd half of the 3rd year respectively. The DPP (Discounted Payback Period) is 2 years, the ROI (Return on Investment) for a 3-year period is 500 percent, and the NPV is $\$ 2,500,000$. The liquidation cost of the project is equal to its basic version development, which means the capital at risk in the case of investing in the project being $\$ 150,000$, and the annual risk-free rate is 5 percent. 
Due to customer demand uncertainty and uncertainty of the project team ability to create a product and achieve declared characteristics the Company considers how to minimize investment risks by analyzing and exploiting available contingencies of the project.

Assuming Prototype, MVP, and Basic Version development costs equal to $\$ 50,000$ each ( $\$ 150,000$ in sum), adding market entry and marketing costs, the project decision tree accounting for all possible decision options and related costs is created for better understanding of how the ROA works in case of innovation project (see fig. 2).

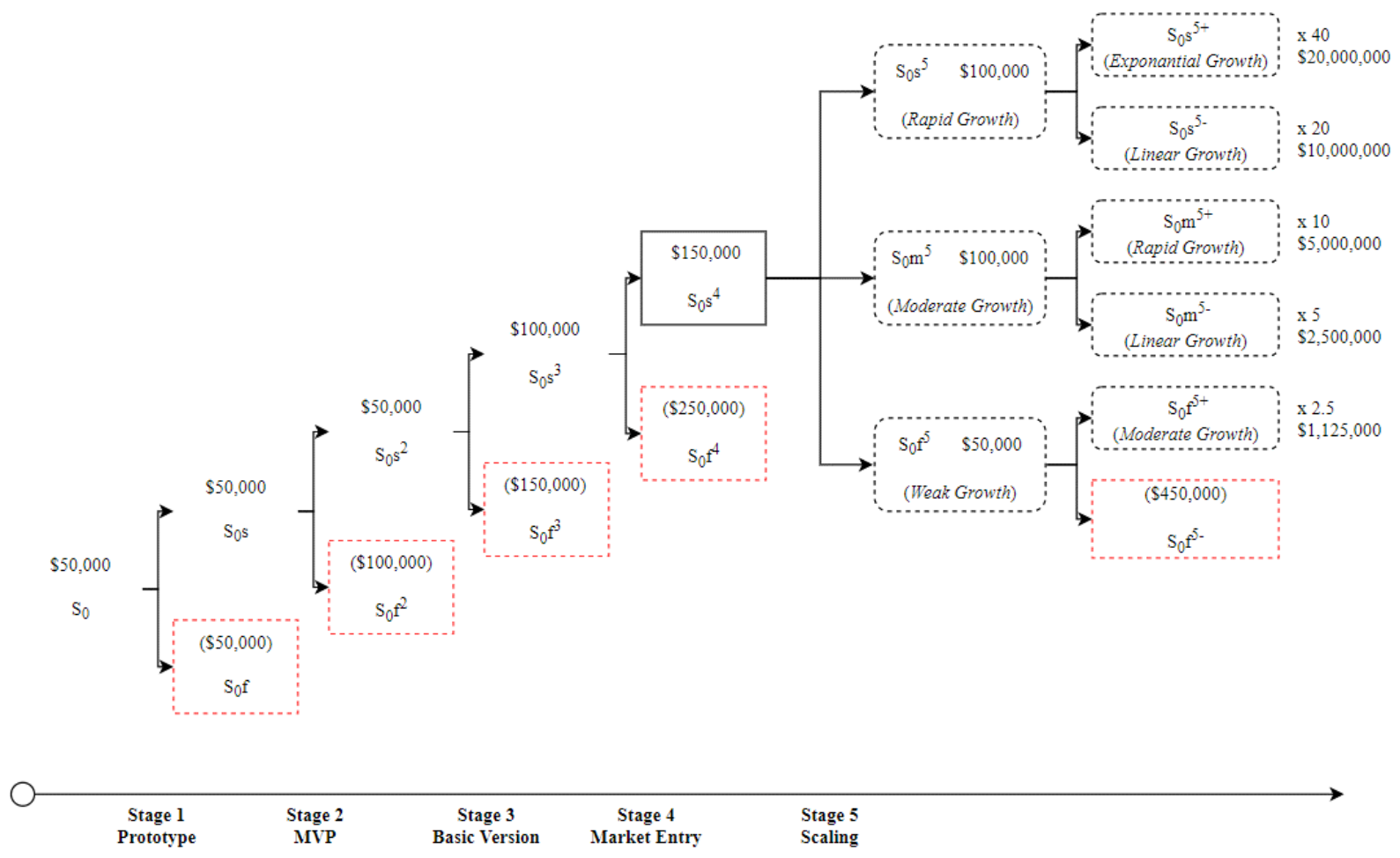

Figure 2. Innovation Project Decision Tree

$\mathrm{S}_{0}$ - or base point - is the stage where the Company decides to invest in the project. If the team competence (H1) and the technological capability (H2) hypotheses are disputed (in other words, the team is not able to create the working prototype), the Company will suspend the implementation of the project ( $\mathrm{S}_{0} \mathrm{f}$ ) fixing losses in the amount of actually invested funds, that is $\$ 50,000$. If the hypotheses are confirmed, the Company will continue developing the project $\left(\mathrm{S}_{0} \mathrm{~s}\right)$ investing in the next stage.

Investing in the MVP development, if at least one of the three hypotheses $(\mathrm{H} 1, \mathrm{H} 2, \mathrm{H} 3)$ is denied, that is, either the team is not able to create the MVP or the product value is not confirmed by its customers, the Company will terminate the project $\left(\mathrm{S}_{0} \mathrm{f}^{2}\right)$ fixing $\$ 100,000$ of losses. If all three hypotheses are confirmed, the Company will continue developing the project $\left(\mathrm{S}_{0} \mathrm{~s}^{2}\right)$ investing in the next stage.

In case of refutation of the hypotheses $\mathrm{H} 2, \mathrm{H} 3, \mathrm{H} 4$ on the basic version stage, the Company will terminate the project $\left(\mathrm{S}_{0} \mathrm{f}^{3}\right)$ fixing $\$ 150,000$ of losses. If hypotheses are confirmed, the Company will continue investing into the project $\left(\mathrm{S}_{0} \mathrm{~s}^{3}\right)$ additional $\$ 100,000$ to launch marketing campaign entering on the market.

Further, if both the H4 and H5 hypotheses are confirmed on the market entry stage, the Company will continue investing $\left(\mathrm{S}_{0} \mathrm{~s}^{4}\right)$, since uncertainty about market demand would be partially dissolved, which now allows to estimate expected cash flows with more confidence. But if at least one of the hypotheses is denied, the Company will suspend the project implementation $\left(\mathrm{S}_{0} \mathrm{f}^{4}\right)$ fixing $\$ 250,000$ of losses.

Having fully confirmed the $\mathrm{H} 4$ and partially $\mathrm{H} 5$ hypotheses, it becomes reasonable to boost marketing costs in order to keep on testing the market depth depending on three possible outcomes, which is rapid growth $\left(\mathrm{S}_{0} \mathrm{~s}^{5}\right)$, moderate growth $\left(\mathrm{S}_{0} \mathrm{~m}^{5}\right)$ or weak growth $\left(\mathrm{S}_{0} \mathrm{f}^{5}\right)$. So the Company has a choice (i) to invest further $\$ 100,000$ in the case of rapid $\left(\mathrm{S}_{0} \mathrm{~s}^{5}\right)$ or moderate $\left(\mathrm{S}_{0} \mathrm{~m}^{5}\right)$ growth, or (ii) $\$ 50,000$ in the case of weak growth $\left(\mathrm{S}_{0} \mathrm{f}^{5}\right)$. 
Assessing investment attractiveness of the project, the Company applies a multiplier to invested capital approach for project valuation, a multiplier method, that varies depending on the final results of the H5 testing:

- In case of rapid exponential growth $\left(\mathrm{S}_{0} \mathrm{~S}^{5+}\right)$ or rapid linear growth $\left(\mathrm{S}_{0} \mathrm{~s}^{5}\right)$, the multiplier will be $\mathrm{x} 40$ or $\mathrm{x} 20$ respectively, which means the project value will be $\$ 20 \mathrm{M}$ or $\$ 10 \mathrm{M}$.

- In case of moderate rapid growth $\left(\mathrm{S}_{0} \mathrm{~m}^{5+}\right)$ or moderate linear growth $\left(\mathrm{S}_{0} \mathrm{~m}^{5-}\right)$, the multiplier will be $\mathrm{x} 10$ or $\mathrm{x} 5$ respectively, and the project value will be $\$ 5 \mathrm{M}$ or $\$ 2.5 \mathrm{M}$.

- In case of weak moderate growth $\left(\mathrm{S}_{0} \mathrm{f}^{5+}\right)$, the multiplier will be $\mathrm{x} 2.5$ with the project value of $\$ 1.125 \mathrm{M}$. Whereas, if the market depth hypothesis is eventually denied, the Company will have to terminate the project $\left(\mathrm{S}_{0} \mathrm{f}^{5-}\right)$ with $\$ 450,000$ of losses.

Next, based altogether on the backward induction approach, the real option method, the hypothesis testing and the multiplier methods, it is applicable to assess the project investment attractiveness (see fig. 3).

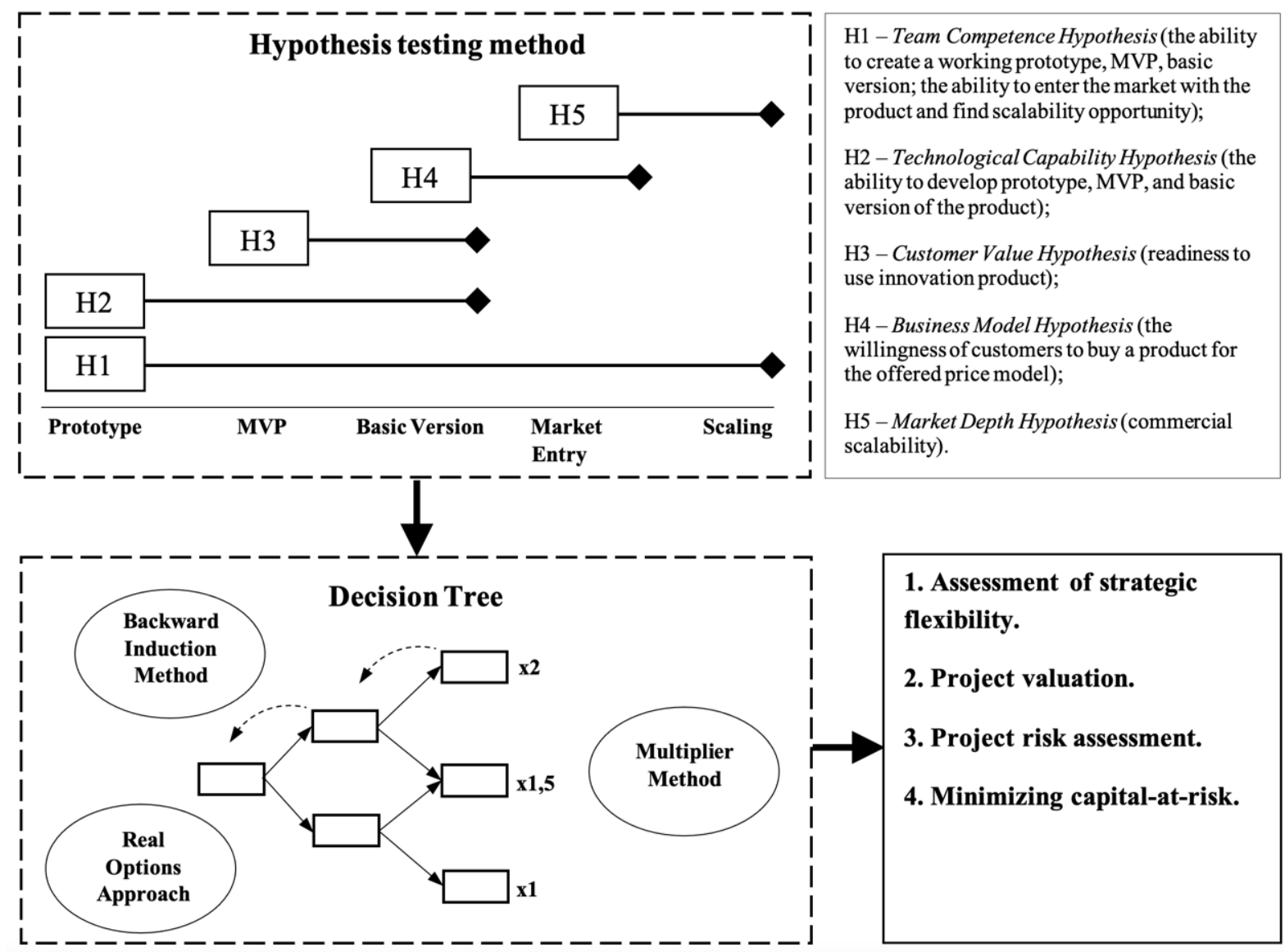

Figure 3. Generalized block diagram for the Hypothesis Testing Method

In order to assess investment attractiveness of an innovation project taking into account its uncertainties, risks and decision-making flexibility, this paper proposes the new approach based on the Hypothesis Testing Method and implies three steps:

1. Build a decision tree by decomposing the project contingencies within its evolution path, minimizing investments on earlier stages and increasing them upon successful testing of underlying hypotheses.

2. Estimate final scenarios depending on the innovative potential of a project using the multiplier method or cash flow forecast if applicable.

3. Calculate option price at each node starting from the last stage and then move back to market entry, basic product, MVP and prototype stages using backward induction logic and ROA.

After assessing an innovation project value, the probability of financial losses (Value-at-Risk modeling) has to be done in order to estimate risk landscape of the project. 
The Hypothesis testing method proposed here is suitable for evaluating any innovation project, but its value significantly increases with the increase in innovativeness degree, as the more innovative the project is (for example disruptive or breakthrough), the more difficult it is to evaluate it with existing methods.

The option price, that reflects net project value, is calculated using the following formula (Smit \& Trigeorgis, 2004):

$$
C=\frac{p\left(V^{+}-I\right)+(1-p)\left(V^{-}-I\right)}{1+r}
$$

where $C$-option price, $p$ - risk-neutral probability, $V^{+}-$the highest project value, $I$ - the amount of investment required), $V^{-}$- the lowest project value, $r$ - risk-free interest rate (rate of return) which is calculated based on annual risk-free rate:

$$
r=\left(1+r_{f}\right)^{n}-1
$$

where $r_{f}$ - annual risk-free rate, $n$ - number of years.

The risk-neutral probability is calculated as follows (Smit \& Trigeorgis, 2004):

$$
p=(1+r) E(V)-\frac{V^{-}}{V^{+-V^{-}}}
$$

where $E(V)$ - expected value of the project.

$$
E(V)=\sum_{i} V_{i} f\left(V_{i}\right)
$$

Using the multiplier method calculate the project value on the end nodes at scaling stage. Then, calculate option prices on each decision tree node starting from the end and then move backward to the left. In order to understand the estimation logic, $\mathrm{S}_{0} \mathrm{~s}^{5}$ node option price will be calculated step-by-step.

For rapid growth $\left(\mathrm{S}_{0} \mathrm{~S}^{5}\right)$ the total investments $(I)$ are $\$ 500,000$, the highest project value $\left(V^{+}\right)$is $\$ 20,000,000\left(\mathrm{~S}_{0} \mathrm{~S}^{5+}\right)$ and the lowest project value $\left(V^{-}\right)$is $\$ 10,000,000\left(\mathrm{~S}_{0} \mathrm{~s}^{5-}\right)$. The risk-free interest rate for the product scaling stage $(r)$ using formula (2) is 0.16 :

$$
(1+0.05)^{3}-1=0.16
$$

Substituting these values into the formula (3) and (4), the risk-neutral probability is equal to 0.74 :

$$
\frac{(1+0.16) x(\$ 20,000,000 \times 0.5+\$ 10,000,000 \times 0.5)-\$ 10,000,000}{\$ 20,000,000-\$ 10,000,000}=0.74
$$

The option price for $\mathrm{S}_{0} \mathrm{~s}^{5}$ node using the formula ( 1 ) is calculated as follows:

$$
C=\frac{0.74 x \$ 19,500,000+(1-0.74) x \$ 9,500,000}{1+0.16}=\$ 14,568,081
$$

To put it another way, $\$ 14,568,081$ is the net project value in case of rapid growth of sales considering its further inherent uncertainty and uncertainties dispelled:

- the team's ability to create a working prototype, MVP and basic version;

- the complexity of the technologies used, their practical applicability and maturity affecting the technological ability to create the product;

- the unique value of the product and customers willingness to use it;

- the customer willingness to buy the product with the offered price model;

- the scale of the problem solved that ensures comprehensive interest from customers and the marketing strategy used.

Using the same logic, the option values on all other nodes of the decision tree are calculated (see fig. 4). 


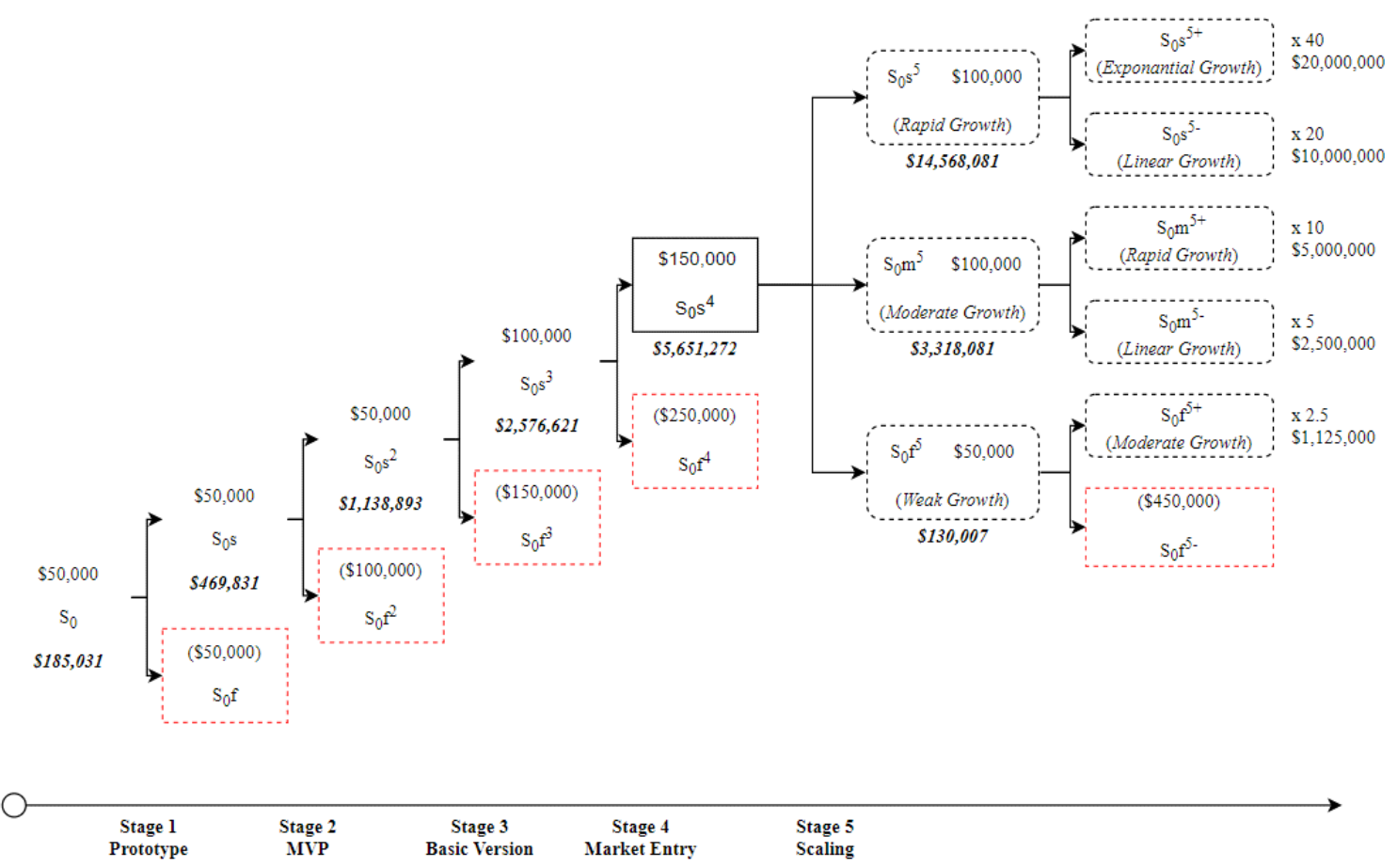

Figure 4. Innovation Project Decision Tree with option prices calculated

That is, the entry cost or net project value at its early stage $\left(S_{0}\right)$ with all inherent uncertainties and managerial decision options (flexibility) related to H1-H5 hypotheses is equal to $\$ 185,031$.

Furthermore, since the $E(V)$ for calculating risk-neutral probability (3) also contains a probabilistic indicator that directly affects the option price (net project value), it makes sense to compare the results by the ordinary and real option decision tree.

As it is shown in fig. 5, for the ordinary decision tree, where the event probabilities are determined and the project value is reduced to the net present value calculated using a discount factor, the expected project values are fairly lower.

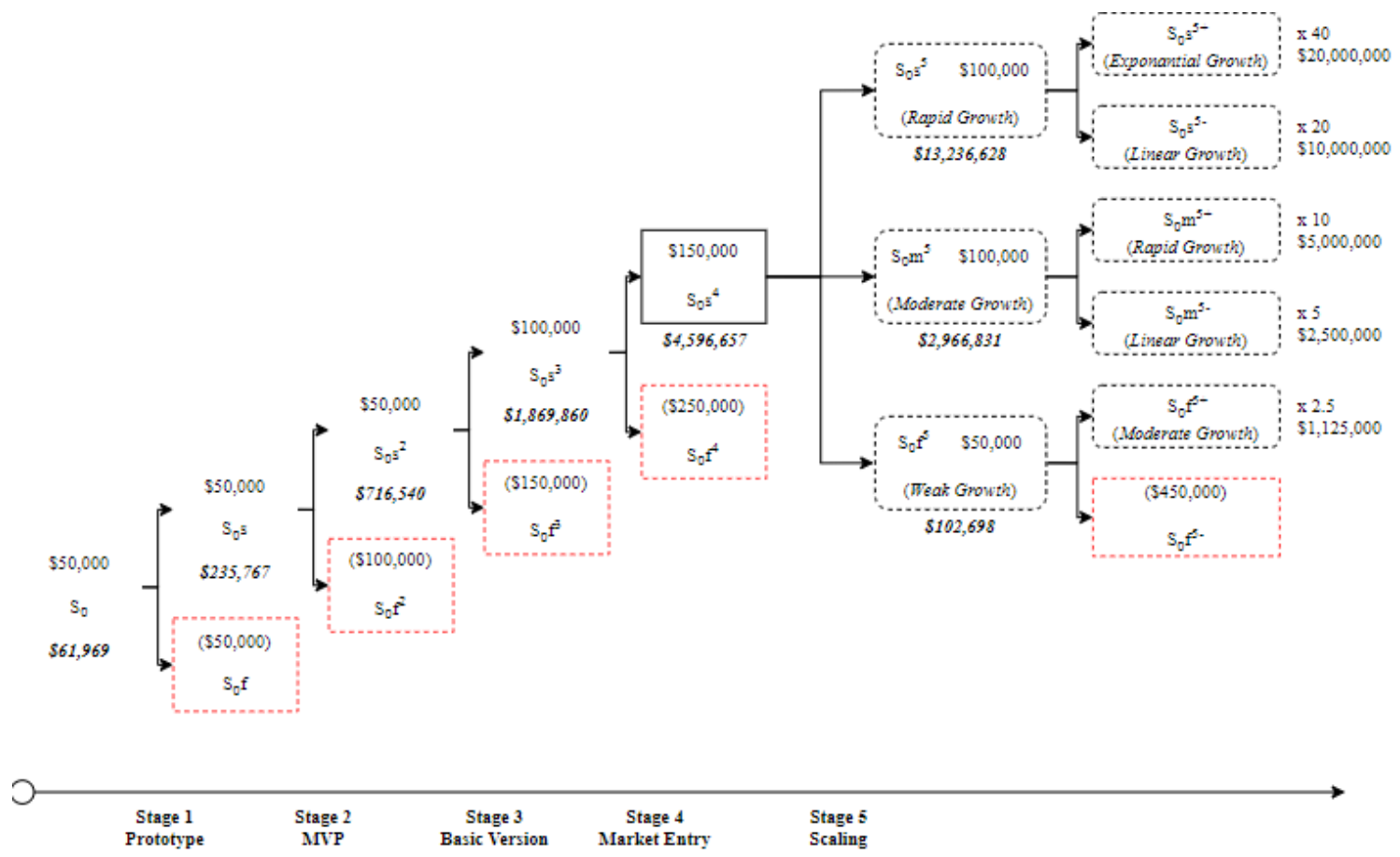

Figure 5. Ordinary Decision Tree with discounted project values 
Thus, the estimated project value under the ordinary decision tree is $\$ 61,969$, which is 3 times less than the value obtained by the real options approach $(\$ 185,031$, see fig. 4$)$, which reduces the project investment attractiveness as well as the chances of getting financing.

Applying sensitivity analysis, the probability factor impact on the expected results from the ROA approach and decision tree were compared. The net project value on the node $S_{0}$ in fig. 4 and the net present value on the node $\mathrm{S}_{0}$ in fig. 5 were re-estimated including possible deviation of the probability factors used to calculate the decision tree and ROA risk-neutral probability on each node using normal distribution (mean 0.5, std. dev. 0.05). Conducting Monte Carlo analysis, the project ROA values (fig. 6, left side) and simple decision tree values (fig. 6 , right side) were calculated.
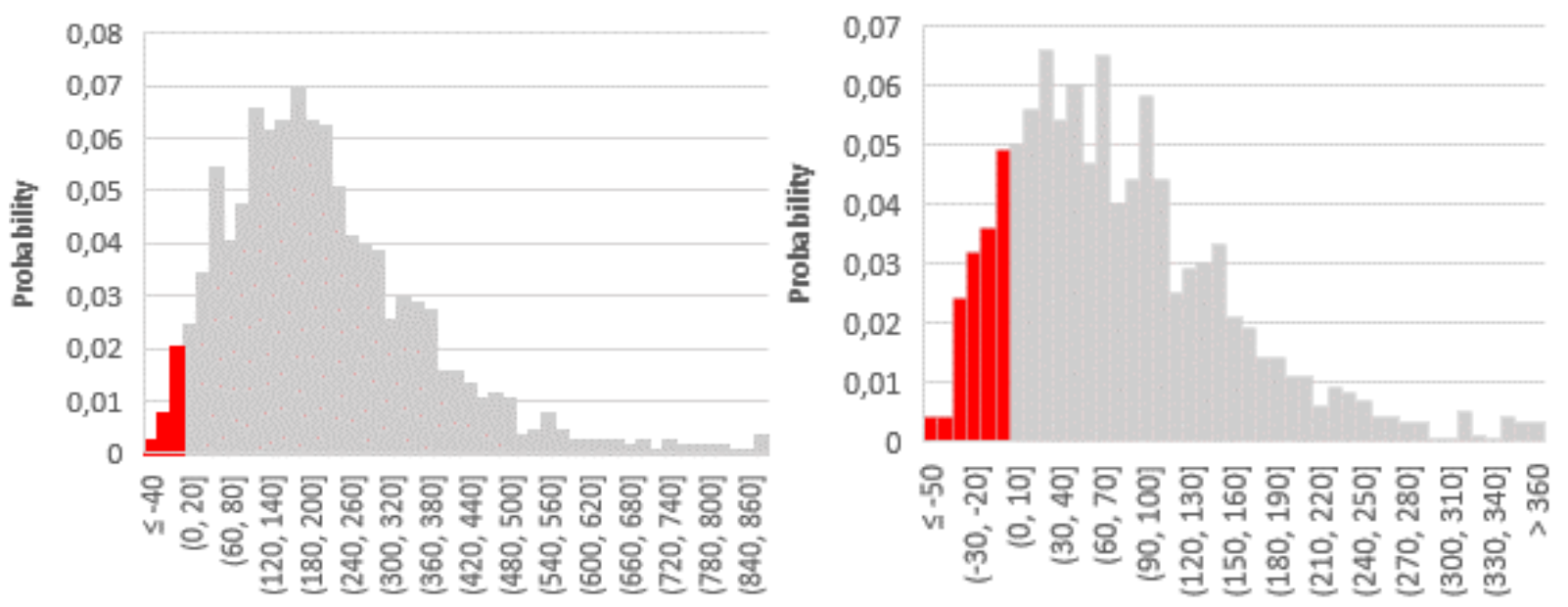

Figure 6. Distribution of the project ROA value (left) and Decision Tree value (right)

Figure 6 graphically shows the initial project value. The $\mathrm{x}$-axis contains all possible values of the project value, and the $y$-axis shows the corresponding probability value. In the 95 percent confidence interval, the project value within ROA methodology will be in the range of $\$ 15,674$ to $\$ 681,466$, instead of $\$-21,326$ to $\$ 298,228$ with the decision tree. Negative values are possible in ROA in contrast to financial option, since the model takes into account the amount of possible losses at each stage.

Evaluating financial risks, the Value-at-Risk $(\operatorname{VaR})$, which is a statistical measure of potential loss that could happen, needs to be estimated. VaR for ROA is 12,6 percent that is, with 0.99 probability, the investor's losses will not exceed 12,6 percent of the net project value at early stage $\left(\mathrm{S}_{0}\right)$. VaR for decision tree is 44,0 percent, so the investor's losses will not exceed 44,0 percent of the project value. Meanwhile, according to the decision tree the project value at early stage may go below zero with the probability of 15,2 percent, while using ROA the probability of going below zero is 1,8 percent.

Now let's get back to standard NPV calculated for the project in the amount of $\$ 2,500,000$, which implies successful product creation and market entry, and the proof of all the underlying hypotheses. Meanwhile, NPV approach methodologically does not have the capability to consider and respectively account all contingencies and respective ups and downs inherent to an innovation project. Obviously, this controversy makes a comparison of standard NPV with the net project value calculated with ROA, that in our case is $\$ 185,031$, irrelevant. In order to compare standard NPV with the option price calculated with ROA, it is necessary to look at the net project value at the market entry stage, which is $\$ 5,651,272\left(\mathrm{~S}_{0}{ }^{4}\right.$ in fig. 4 ) or 126.1 percent higher than the project standard NPV calculated using the DCF approach (see fig. 7). The innovation project investment attractiveness is more than 2 times higher if it is estimated using the ROA, which significantly increases the chances of investors entering the project and its practical realization. Another significant advantage is the fact that the ROA also evaluates each of the innovation creation steps that cannot be done by simple NPV. 


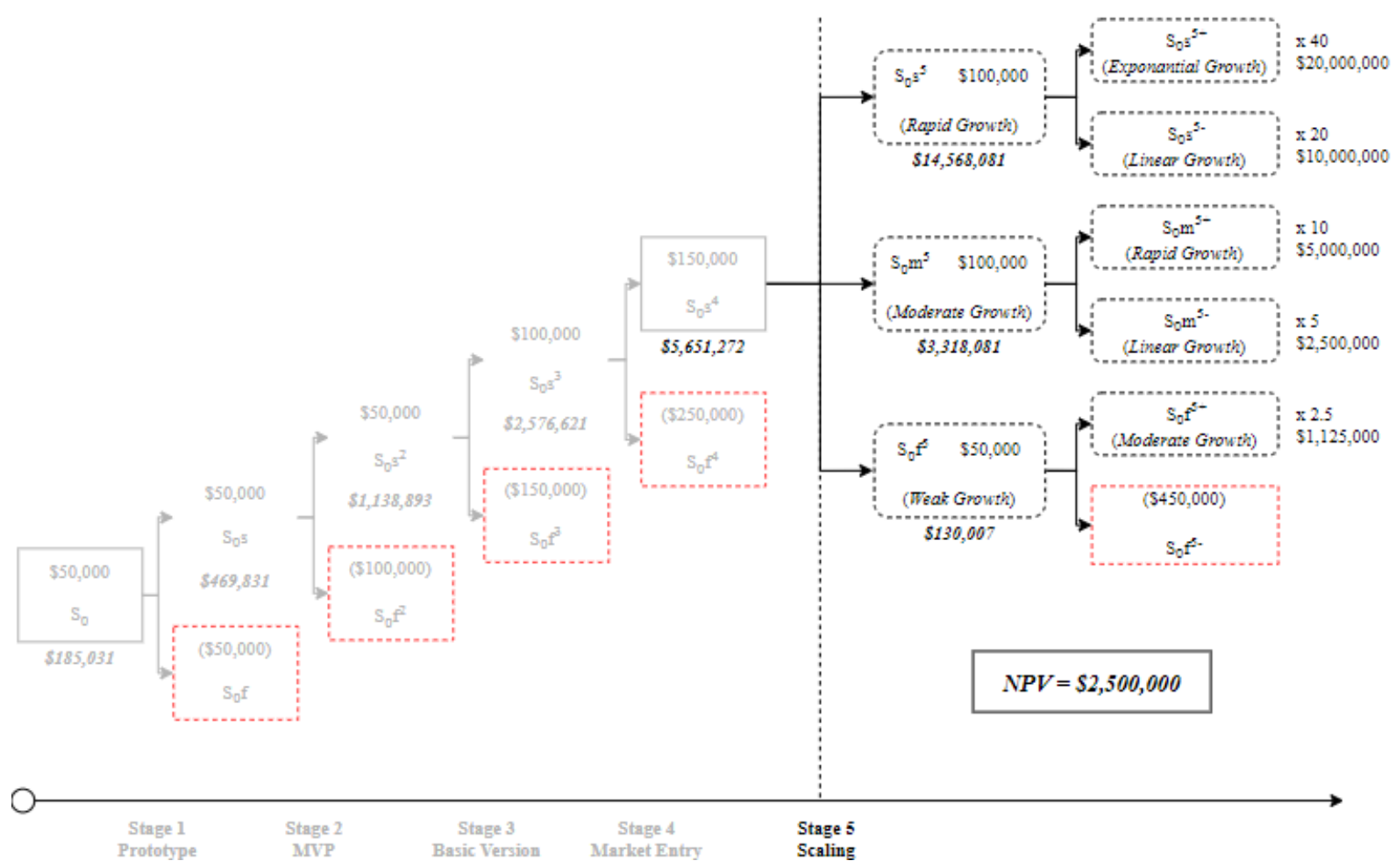

Figure 7. ROA Decision tree versus NPV approach

Omitting the entire period of innovation development and evaluating only the product sales stage (scaling), standard NPV significantly reduces the project investment attractiveness and embedded flexibility to minimize sunk costs and maximize upsides, and is not an appropriate method of evaluating projects that are subject to significant uncertainty and risks. Instead of that, the approach proposed, unlike the existing methods of evaluating innovation opportunities, involves the project life cycle stages and underlying hypotheses.

\section{Discussion}

Due to inherent uncertainty and related risks of innovations, prediction of future optimal decisions looks like a vague idea, but it is not a reason for excluding managerial flexibility from taking into consideration while assessing innovation projects. Evaluating investment attractiveness of an innovation opportunity, its profitability, considering inherent contingencies and minimizing financial losses, should include available managerial options during the project's lifetime.

Real option and decision tree analysis are useful tools for assessing strategic landscape and respective investment decisions. ROA corrects NPV value by incorporating flexibility of managerial decision making, which allows to reconsider uncertain situations and adopt them into simpler analytical structures. However, at the same time, ROA is a financial innovation assessment tool, most suitable for assessing an innovative project, which has been known for many years. Estimating the innovation project, this paper proposes a completely new approach that allows an investor to look differently at innovation development. This article describes the mechanism for reassessing the risks of innovation at each innovation project development stage, which allows to build risk clusters and understand the likelihood of project implementation failure competently.

Since every innovation project goes through prototyping, MPV and basic version development, market entry, and scaling, we propose to consider in detail uncertainties and risks inherent to these stages reflected in the five hypotheses which are the Team competence (H1), Technological capability (H2), Customer value (H3), Business model (H4), and Market depth (H5) hypotheses.

Evaluating project exclusively based on its cash flows, there is a bulge in understanding the real risks of its failure. The proposed Hypothesis testing method, which is superimposed on ROA, backward induction and multiplier method, allows to shift focus to risk assessment of innovation projects.

Other distinguishing features of the Hypothesis testing method approach are: 
1. Independence from a discount factor.

2. Using risk-neutral probability instead of subjective probabilities.

3. Hands-on applicability of ROA as it accounts to managerial flexibility during an innovation project lifetime, unlike NPV.

4. Minimizing the impact of project duration on its value. In the DCF approach all calculations are subject to the time factor, however, in case of innovations a project duration can differ significantly from expected one. Estimating an innovation project using the DCF method, the output will differ significantly, whereas within the ROA the deviation is minimized.

5. Minimizing capital-at-risk usually considered as a whole investment cost.

6. Focus on the phased success, which allows to reconsider project related risks based on the information obtained after the uncertainties have been cleared in the previous stage.

The proposed innovation project evaluation method is a logical extension of the real option theory as a competitive approach to the assessment of investment opportunity with a high level of uncertainty. By shifting attention from the cash flow that will occur only after the successful product implementation (which implies the successful completion of all stages of product development, as well as marketing and sales launching) to testing the hypotheses at each stage of the innovation project, it is possible to explore all possible risks separately and overestimate these risks in iterative logic for deeper understanding of the investment opportunity. This is a new paradigm in risk assessment of innovations.

Evaluation of an innovation project due to inherent uncertainty should cover all stages of innovative product creation, starting with an idea to scaling on the market. Each stage is fraught with uncertainty and risks that can be outlined by testing of appropriate hypothesis. The Hypothesis testing method in the context of the evolution of an innovation product allows to investigate project risks, isolate clusters of uncertainty and identify differentiated risks of team, technology, customer value, business model and market depth, which in turn allows to make a more informed investment decision by reassessing the risks and opportunities based on the hypotheses inherent with each stage of the innovation project.

Applying the ROA to assess the innovation project investment attractiveness is a conceptually correct decision, as it involves both the ability to assess managerial flexibility and the departure from risk aggregation in the discount rate factor.

The substitution of classical valuation methods for innovations is a logical and necessary way, since the inclusion of strategic flexibility and minimization of capital at risk by using the Hypothesis testing method are features that allow investor to make more accurate management decision and avoid missing the breakthrough opportunities. This approach changes the direction of the innovation assessment process from the financial component that is present after sales began, to all stages of creating an innovation, starting from the idea generation, in order to describe the main risks of the project as fully as possible. This method is flexible, which allows it to be used for projects of different areas. It can also be expanded by adding assumptions to the underlying hypotheses or narrowed down if one or more hypotheses have already been tested and the uncertainty about these risks is completely dispelled.

\section{References}

Bell, M., \& Pavitt, K. (1995). The Development of Technological Capabilities. In: Trade, Technology and International Competitiveness. Washington: The World Bank.

Berglund, H., \& Sandström, C. (2013). Business Model Innovation from an Open Systems Perspective: Structural Challenges and Managerial Solutions. International Journal of Product Development, 18(3/4), 274-285. https://doi.org/10.1504/IJPD.2013.055011

Bowers, J. A., Khorakian, A. (2014). Integrating risk management in the innovation project. European Journal of Innovation Management, 17(1), 25-40. https://doi.org/10.1108/EJIM-01-2013-0010

Brandão, L., Dyer, J. S. (2005). Decision Analysis and Real Options: A Discrete Time Approach to Real Option Valuation. Annals of Operations Research, 1-25. https://doi.org/10.1007/s10479-005-6233-9

Casadesus-Masanell, R., \& Zhu, F. (2013). Business model innovation and competitive imitation: The case of sponsor-based business models. Strategic Management Journal, 34(4), 464-482. https://doi.org/10.1002/smj.2022

Cassia, L., Plati, A., \& Vismara, S. (2007). Equity valuation using DCF: A theoretical analysis of the Long Term hypotheses. Investment Management and Financial Innovations, 4(1), 91-107. 
Cesário, M., \& Fernandes, S. (2019). Smart innovation strategy and innovation performance: An empirical application on the Portuguese small and medium-sized firms. Regional Science Policy \& Practice, 11(6), 969982. https://doi.org/10.1111/rsp3.12149

Chambers, C. P., \& Echenique, F. (2018). On Multiple Discount Rates. Econometrica, 86(4), 1325-1346. https://doi.org/10.3982/ECTA14866

Chappin, M. M. H., Faber, J., \& Meeus, M. T. H. (2019). Learning patterns in early-stage R\&D projects: empirical evidence from the fibre raw material technology project in the Netherlands. R\&D Management, 49(4), 684695. https://doi.org/10.1111/radm.12358

Chesbrough, H. (2010). Business Model Innovation: Opportunities and Barriers. Long Range Planning, 43(2), 354-363. https://doi.org/10.1016/j.lrp.2009.07.010

Chesbrough, H., Lettl, C., \& Ritter T. (2018). Value Creation and Value Capture in Open Innovation. Journal of Product Innovation Management, 35(6), 930-938. https://doi.org/10.1111/jpim.12471

Cooper, R. G. (2010). The Stage-Gate Idea to Launch System. Wiley International Encyclopedia of Marketing: 19. https://doi.org/10.1002/9781444316568.wiem05014

Cooper, R. G. (2011). Winning at new products: Creating value through innovation (4th ed.). New York: Basic Books.

Cooper, R. G. (2014). What's next? After Stage-Gate. Research-Technology Management, 157(1), 20-31. https://doi.org/10.5437/08956308X5606963

Cooper, R. G. (2016). Agile-Stage-Gate hybrids: The next stage for product development. Research-Technology Management, 159(1), 21-29. https://doi.org/10.1080/08956308.2016.1117317

Cooper, R. G., \& Sommer, A. F. (2016). The Agile-Stage-Gate Hybrid Model: A Promising New Approach and a New Research Opportunity. Journal of Product Innovation Management, 33(5), 1-14. https://doi.org/10.1111/jpim.12314

Correia, C., Flynn, D., Uliana. E., \& Wormald, M. (2007). Financial management. 6th edition. Cape Town: Juta.

Damodaran, A. (2002). Investment Valuation: Tools \& Techniques for Determining Any Asset. New York: John Wiley \& Sons.

Drucker, P. F., Christensen, C. M., \& Govindarajan, V. (2013). HBR's 10 Must Reads on Innovation. Harvard Business Review.

Ettlie, J. E., \& Elsenbach, J. M. (2006). Modified Stage-Gate ${ }^{\circledR}$ Regimes in New Product Development. Journal of Product Innovation Management, 24(1), 20-33. https://doi.org/10.1111/j.1540-5885.2006.00230.x

Frank, A. G., Ribeiro, J. L. D., Cortimiglia, M. N., \& Oliveira, L. S. (2016). The effect of innovation activities on innovation outputs in the Brazilian industry: Market-orientation vs. technology-acquisition strategies. Research Policy, 45, 577-592. https://doi.org/10.1016/j.respol.2015.11.011

Furr, N., \& Dyer, J. (2014). The Innovator's Method: Bringing the Lean Start-up into Your Organization. Brighton: Harvard Business Review.

Gans, J. (2016). The disruption dilemma. Cambridge, MA: The MIT Press. https://doi.org/10.7551/mitpress/9780262034487.001.0001

Garcia, R., \& Calantone R. (2002). A critical look at technological innovation typology and innovativeness terminology: a literature review. The Journal of Product Innovation Management, 19, 110-132. https://doi.org/10.1111/1540-5885.1920110

Goffin, K., \& Mitchell R. (2017). Innovation Management: Effective strategy and implementation. London, UK: Palgrave Macmillan. https://doi.org/10.1057/978-1-137-37344-1

Hartwig, S., \& Mathews, S. (2020). Innovation Project Risk Analytics: A Preliminary Finding. ResearchTechnology Management, 63, 19-23. https://doi.org/10.1080/08956308.2020.1733901

Hurst, P. (1982). Ideas into action development and the acceptance of innovations. International Journal of Educational Development, 1, 79-102. https://doi.org/10.1016/0738-0593(82)90046-3

Keller, R. T. (2017). A longitudinal study of the individual characteristics of effective R\&D project team leaders. $R \& D$ Management, 47(5), 741-754. https://doi.org/10.1111/radm.12272

Kerzner, H. (2019). Innovation Project Management: Methods, Case Studies, and Tools for Managing Innovation 
Projects. Wiley. https://doi.org/10.1002/9781119587408

Kock, A., \& Gemünden, H. G. (2020). How entrepreneurial orientation can leverage innovation project portfolio management. R\&D Management, 1-17. https://doi.org/10.1111/radm.12423

Kodukula, P., \& Papudesu, C. (2006). Project Valuation Using Real Options: a Practitioner's Guide. Florida: J. Ross Publishing, Inc.

Latimore, D. (2002). IBM Institute for Business Value. NY: IBM Corporation.

Loch, C. H., Solt, M. E., \& Bailey, E. M. (2007). Diagnosing Unforeseeable Uncertainty in a New Venture. The Journal of Product Innovation Management, 7, 28-46. https://doi.org/10.1111/j.1540-5885.2007.00281.x

Marion, T. J., \& Fixson, S. K. (2020). The Transformation of the Innovation Process: How Digital Tools are Changing Work, Collaboration, and Organizations in New Product Development. Journal of Product Innovation Management. https://doi.org/10.1111/jpim.12547

Mathews, S., \& Russell, P. (2020). Risk Analytics for Innovation Projects. Research-Technology Management, 63, 58-63. https://doi.org/10.1080/08956308.2020.1707012

McGrath, R. G. (2010). Business Models: A Discovery Driven Approach. Long Range Planning, 43(2-3), 247-261. https://doi.org/10.1016/j.lrp.2009.07.005

Melkas, H., \& Harmaakorpi, V. (2011). Practice-Based Innovation: Insights, Applications and Policy Implications. Springer. https://doi.org/10.1007/978-3-642-21723-4

Nagji, B., \& Tuff, G. (2012). Managing your Innovation Portfolio. Harvard Business Review, 66-74.

Ohlson, J. A. (2003). Positive (Zero) NPV Projects and the Behavior of Residual Earnings. Journal of Business Finance \& Accounting, 30(1), 7-16. https://doi.org/10.1111/1468-5957.00480

Ohlson, J. A. (2003). Positive (Zero) NPV Projects and the Behavior of Residual Earnings. Journal of Business Finance \& Accounting, 30(1-2), 7-16. https://doi.org/10.1111/1468-5957.00480

Paulsen, N., Maldonado, D., Callan, V. J., \& Ayoko, O. (2009). Charismatic leadership, change and innovation in an R\&D organization. Journal of Organizational Change Management, 22(5), 511-523. https://doi.org/10.1108/09534810910983479

Pinto, J., \& Mantel, S. (1990). The Cause of Project Failure. IEEE Transactions on Engineering Management, 37, 269-276. https://doi.org/10.1109/17.62322

Que, J., \& Zhang, X. (2020). The role of foreign and domestic venture capital in innovation: evidence from China. Accounting \& Finance, 60(51), 1077-1110. https://doi.org/10.1111/acfi.12401

Rong, Z., \& Xiao, S. (2016). Innovation-Related Diversification and Firm Value. European Financial Management, 23(3), 475-518. https://doi.org/10.1111/eufm.12110

Sánchez-Fernández, Raquel, M., Ángeles, I. B., \& Morris, B. H. (2009). The Conceptualisation and Measurement of Consumer Value in Services. International Journal of Market Research, 51, 93-113. https://doi.org/10.1177/147078530905100108

Sandström, C., Berglund, H., \& Magnusson, M. (2014). Symmetric Assumptions in the Theory of Disruptive Innovation: Theoretical and Managerial Implications. Creativity and Innovation Management, 23(4), 1-28. https://doi.org/10.1111/caim.12092

Shestakov, D. (2018). Understanding Innovation: Process, Project and Product-Centric Views. Efektyvna ekonomika, 12, 1-10. https://doi.org/10.32702/2307-2105-2018.12.209

Shestakov, D., \& Poliarush, O. (2019). The degree of innovation: through incremental to radical. Investytsiyi: praktyka ta dosvid, 11, 66-75. https://doi.org/10.32702/2306-6814.2019.11.66

Sick, G., \& Gamba A. (2005). Some Important Issues Involving Real Options. Finance, 14(1), 1-45.

Smit, H. T. J., \& Trigeorgis, L. (2004). Strategic Investment: Real Options and Games. Princeton: Princeton University Press. https://doi.org/10.1515/9781400829392

Smit, H. T. J., \& Trigeorgis, L. (2017). Strategic NPV: Real Options and Strategic Games under Different Information Structures. Strategic Management Journal, 38(13), 2555-2578. https://doi.org/10.1002/smj.2665

Spanjol, J., Mühlmeier, S., \& Tomczak, T. (2012). Strategic Orientation and Product Innovation: Exploring a Decompositional Approach. Journal of Product Innovation Management, 29(6), 967-985. https://doi.org/10.1111/j.1540-5885.2012.00975.x 
Taylor, J. E., \& Levitt, R. (2007). Innovation alignment and project network dynamics: An integrative model for change. Project Management Journal, 38(3), 22-35. https://doi.org/10.1002/pmj.20003

Tohidi, H. (2012). Different Stages of Innovation Process. Procedia Technology, 1, 574-578. https://doi.org/10.1016/j.protcy.2012.02.125

Trimi, S., \& Berbegal-Mirabent, J. (2012). Business Model Innovation in Entrepreneurship. International Entrepreneurship and Management Journal, 8(4), 449-465. https://doi.org/10.1007/s11365-012-0234-3

Tsang, E. W. K. (2006). Behavioral assumptions and theory development: The case of transaction cost economics. Strategic Management Journal, 27(11), 999-1011. https://doi.org/10.1002/smj.553

Wang, J. (2017). Structuring innovation funnels for R\&D projects under uncertainty. R\&D Management, 47(1), 127-140. https://doi.org/10.1111/radm.12183

Young, K. M. (2020). Long-Term R\&D Strategy and Planning. Research-Technology Management, 63, 18-26. https://doi.org/10.1080/08956308.2020.1707002

Zawislak, P. A., Alves, A., Tello-Gamarra, J., Barbieux, D., \& Reichert, F. M. (2012). Innovation capability: from technology development to transaction capability. Journal of Technology Management \& Innovation, 7(2), 14-27. https://doi.org/10.4067/S0718-27242012000200002

Zhou, K., \& Li, C. (2012). How knowledge affects radical innovation: Knowledge base, market knowledge acquisition, and internal knowledge sharing. Strategic Management Journal, 33(9), 1090-1102. https://doi.org/10.1002/smj.1959

Zizlavsky, O. (2014). Net Present Value Approach: Method for Economic Assessment of Innovation Projects. Procedia - Social and Behavioral Sciences, 156, 506-512. https://doi.org/10.1016/j.sbspro.2014.11.230

\section{Copyrights}

Copyright for this article is retained by the author(s), with first publication rights granted to the journal.

This is an open-access article distributed under the terms and conditions of the Creative Commons Attribution license (http://creativecommons.org/licenses/by/4.0/). 